\title{
On the Theory of Social Insurance
}

\section{- Comments on "The State and the Demand for Security in Contemporary Societies"}

\author{
by Joseph E. Stiglitz *
}

Professor Barre has presented us with an extremely stimulating paper. He notes that a significant proportion of the increase in public expenditures in the past quarter century have been concerned with reducing the risks which individuals face, with providing a variety of forms of social insurance. To finance these social security programs governments have had to raise taxes to rates which impose significant distortions on the economy and/or have resorted to deficit financing, with resulting inflation. Some reforms are clearly necessary, reforms which necessitate a reassessment of the roles of the private versus public sector in the provision of insurance. Professor Barre suggests several specific reforms with which I am in considerable sympathy.

In my remarks, I wish to address three questions :

First, how can we explain the rapid rise of the role of government in risk bearing ?

Second, how can we explain the difficulties which these social insurance programmes, all over the world, seem to be facing ?

And third, what guidelines can we give for policy, both in the design of public insurance programmes, and in the decisions about the appropriate balance between the public and private sectors in insurance.

The widespread public demand for social insurance has, I think, two roots. It is partly a response to a failure of the private sector to provide adequate mechanisms by which individuals can divest themselves of the risks which they face. Some of this failure is understandable : (a) economists have identified two broad categories of risks, those which are diversifiable and those which are not (sometimes referred to as social risks), risks which society as a whole (or all the members of the generation alive at a particular time) face together. The insurance firm which insures a large number of individuals can predict fairly accurately the number of individuals who will die each year. But if there is a war, then the number of individuals who die may be much larger. Thus, most insurance policies exclude the coverage of death in a war. When the economy goes into a recession or depression, the number of unemployed individuals increases markedly. The likelihood of one individual's being unemployed is not

\footnotetext{
* Princeton University.
} 
independent of that of another individual's being unemployed. Similarly, if an insurance firm insured against inflation, it would find that if the inflation rate increases much faster than it had expected, it would bear a loss on all of its insurance policies ; it might well find that it would not able to meet all of these commitments at the same time.

How, one might ask, can society insure its members against such risks any better than an insurance firm ? Society is worse off, because it has to fight a war, or because recession has interfered with its ability to use its resources to capacity; such events obviously affect some individuals more than others, and thus some are in a position to absorb some of the costs of these events from others. But if this is so, why cannot they do this through the private market? There is no really good answer to this question: the fact remains that private markets have not taken an active role in sharing some of these essential risks, and when they have, they have done it at a very high cost.

There is one major distinction between the possibilities of risk sharing available to the market and those available to the government ; the government can engage in risk sharing across generations. The costs of a war, for instance, can be shared between the current generation and future generations; by reducing investment during the period of the war, and by subsequently imposing taxes on the young for the benefit of the old, the costs of the war can effectively be shared between the generation which is working during the period of the war and subsequent generations. As important as the intergenerational risk sharing may be in practice, it has provided little of the rationale for social insurance programs.

(b) There are other risks where issues of moral hazard or adverse selection loom large. The provision of insurance often has important incentive effects ; the individual's incentives to avoid the insured-for event may be markedly reduced; and the more complete the insurance coverage, the more incentives are reduced. Thus, an individual who insures property for $110 \%$ of its value not only has no incentive to avoid a fire, but actually has an incentive to cause a fire to occur. In the insurance industry, these incentive problems are referred to as the "moral hazard problem". One consequence of the moral hazard problem is that insurance companies are reluctant to write insurance providing complete coverage for many types of risks. Thus medical insurance policies often entail the individual paying a fraction $(20 \%)$ of the costs of medical care. The skyrocketing medical costs under Medicare may be partly attributable to the fact that the government has failed to recognize these important incentive problems.

The failure of the private market to provide complete insurance should not be viewed as a capricious consequence of rapacious insurance companies trying to exploit the hopeless consumer, but rather as a rational response to a critical economic problem, of providing at least some incentives to the insured. To the extent that this provides an explanation of the limitations of insurance provided by the private market, there is no reason to believe that the government can do any better : the trade-offs between risk reduction and incentives remain the same.

The other problem which confronts private insurance markets is that there is an incentive for the worst risks to sign up for insurance, while the best risks self-insure. This is referred to as the problem of adverse selection. It arises because individuals know more about the likelyhood of the insured-for event occurring than the insurance 
company ; although the insurance company may attempt to discriminate between good risks and bad risks, it can only do so imperfectly. There is a sense in which the governments has an advantage over the private market, because it can force all individuals to purchase the insurance to avoid the problem of adverse selection. In doing so, it is engaging in some redistribution; good risks are paying more than they "ought to" ; bad risks less than they should. 1

But while the limitations on private insurance markets that we have just discussed are understandable, some of the failures of the private sector are not so easy to explain.

There are three limitations, in particular, to which I would like to call attention. (a) The ratio of benefits to premiums for many types of insurance are low ; while the government may have a bad reputation for administrative inefficiency, the expenditures on administration for many forms of public insurance are considerably less than for private insurance. Though a significant fraction of the difference in expenses may be accounted for by marketing or selling costs, the question is, are the benefits provided by competitive selling - the greater diversity of policies, the ability to tailor the insurance more finely to the needs of the individual, and the seemingly greater incentive for efficiency and quality - are these benefits worth the extra costs ?

The low ratio of benefit to premium characterizes not only casualty insurance but also life insurance. There have been numerous studies suggesting that the before tax rate of return on many forms of permanent life insurance is significantly lower than that on other forms of comparably safe investment. These forms of insurance have been viable, partly because of lack of information - or perhaps rationality - on the part of consumers, and partly because of the favorable tax treatment of this form of savings. Should the differential tax treatment change (and there is some evidence that this may occur in the not too distant future) and should consumers become more informed (or rational) the industry may well be in for difficult times.

(b) The insurance industry has failed to provide insurance for many of the kinds of risks, for which there should be insurance. There is no reason that natural disasters, like floods, should not be insurable so long as they are relatively local in character. It has only been in the last few decades that individuals could easily purchase major medical insurance. Insurance companies have perhaps spent too much of their attention insuring minor risks - risks which the individual would be better off insuring himself, like automobile towing - and too little of their attention focusing on the major risks for which the individual cannot self insure.

(c) The insurance industry has, at times, attempted to suppress those competitive forces which would lead to greater efficiency within the industry and to a better adaptation of the industry to the needs of the population. I have in mind here the restrictions imposed on savings banks providing insurance, as well as the legislation restricting the Federal Trade Commission for attempting to promote competition and increase the level of consumer information in the insurance industry.

1 Recent theoretical research on the theory of competitive markets with moral hazard and with adverse selection problems has shown that equilibrium may not exist, and when it does it may not be Pareto efficient. See Rothschild and Stiglitz (1976) [3] and Arnott and Stiglitz (1983) [1]. 
The limitations on private insurance markets which we have just described provide, however, only part of the impetus for our major social insurance programmes.

There is a second genesis to the demand for public insurance that is less well founded. A compassionate society must pay attention to the needy within it, and many of those who are in need are there because of some event, some accident, which is, in principle, insurable. It is reasonable that society should attempt to ensure that their needs are taken care of in one way or another, and accordingly, that it ensure that individuals have some basic insurance coverage for a variety of the more important risks which individuals face. But public policy in this area has, I think, made four mistakes.

First, if society believes that it cannot countermark older individuals suffering because of inadequate provision for their retirement years, and if a number of individuals fail to make adequate provision for their retirement on their own, there is an argument for compelling individuals to do so. For those who do make provision for their retirement may feel that it is unfair that they should have to bear the burden of those who could have made adequate provision for their retirement but simply had insufficient foresight to do so. In this view, retirement insurance (or life insurance) is a merit want, a good which a paternalistic government insists on the individual purchasing, whether he chooses to do so of his own accord or not. But it is a merit good which is different from many other merit goods, because a significant part of the costs of the individual's failure to purchase the good is borne by others. However, to the extent that this provides the rationale for social insurance, it suggests that the government require that individuals obtain insurance, but it does not imply that the government should require that individuals purchase the insurance from the government itself.

The government has confused the question of whether individuals are to be insured with the question of who is to provide the insurance. The view that society must take measures to ensure that everyone is insured against certain major risks does not, in itself, imply that the government should directly provide that insurance.

Second, it has confused issues of social insurance with those of redistribution. As a society, we may wish to redistribute income from the rich to the poor, but are the aged poor any more deserving than the poor Indian or blacks who are unemployed? Should we redistribute income from the middle class working man to the aged individual whose income - including returns from securities - exceeds that of the representative taxpayer?

Thirdly, it has forgotten that one of the primary reasons that markets failed to provide insurance is what we referred to earlier as the problem of moral hazard : the provision of insurance affects individuals' action ; when medical expenses are paid by a third party, whether the government or an insurance company, it is no wonder that there are no incentives for limiting cost increases. If unemployed individuals receive almost as much pay as the employed, what incentive do they have to seek out work? And when working, what incentive do they have not to shirk?

Finally, the government has systematically ignored the budgetary implications of its social insurance programs. These budgetary implications are finally and regretfully, becoming apparent : they are the result, on the one hand, of ignoring the incentive problems referred to above, and on the other, of having on excessively ambitious 
redistribution program combined with the social insurance program. As long as the population and the economy were growing rapidly, each generation could, in effect, borrow against the next (in a kind of Ponzi scheme). If, for instance, population is growing at $3 \%$, each member of one generation can give one dollar to his parents, and receive $\$ 1.03$ from his children. But every Chain letter come to an end the day of reckoning may not be far off. It is unlikely that members of my generation, and certainly the members of my children's generation, can receive the benefits which we promise to our parents. There are important issues of intergenerational equity that must be confronted, but the appropriate way to do this is not in the exigencies of budgetary cuts.

This brings me to my final question : where are we to go from here? Professor Barre in his lecture has emphasized the importance of restructuring the insurance programs to provide better incentives, and with this I strongly concur.

There are four further tentative suggestions, which I would like to put before you for your consideration.

First, a clearer distinction should be made between the redistributive and insurance aspects of social insurance programmes. The insurance component should be provided on an actuarially sound basis. The government may decide to give to some individuals more than they have contributed, but these redistributions should be brought out into the open. No one should be fooled into thinking he has "paid" for several insurance benefits which he has not paid for. This will enable a more responsible debate about the appropriate allocation of subsidies: should the aged poor, for instance, receive more than the early poor?

Secondly, if the primary objective of public insurance is to ensure that the needy get taken care of, that they not fall through the safety net, should not the compulsory part of social insurance be limited to providing these basic needs ?

Thirdly, might not a "voucher" scheme, of the kind widely discussed for education, enable individuals to exercise choice and, at the same time, provide incentives for the efficient administration and design of insurance programmes?

Fourthly, shouldn't the government take as active a role in promoting competition within the insurance industry as it takes in other sectors of the economy at the very least, it should take actions to remove the barriers to competition which it has constructed.

\section{REFERENCES}

1. ARNOTT, R. J., and STIGLITZ, J. E. : "Equilibrium in Competitive Insurance Markets : The Welfare Economics of Moral Hazard," 1982 (Part I : The Basis Analytics of Consumers Behavior in Insurance Markets with Moral Hazard; Part II : Competitive Equilibrium ; Part III : Welfare Economics), Institute for Economic Research, Queen's University. 
2. BARRE, R.: “The State and The Demand for Security in Contemporary Societies", Sixth Annual Lecture of the Geneva Association, 1982.

3. ROTHSCHILD, M., and STIGLITZ, J. [1976]: "Equilibrium in competitive insurance markets : An essay on the economics of imperfect information ", Quarterly Journal of Economics, 90 (November 1976), 629-649.

4. STIGLITZ, J.E. [1983] : "Risk, incentive and insurance: The pure theory of moral hazard", The Geneva Papers on Risk and Insurance, 8 (January 1983), 4-33. 